\title{
Reinventing the Wheel: Contextualizing Existing Innovations as a Path to Market Success
}

Jeff Moretz, Karthik Sankaranarayanan, and Jennifer Percival

\author{
(6 Creativity is not the finding of a thing, but the") \\ making something out of it after it is found.
}

James Russell Lowell (1819-1891)

Poet, critic, editor, and diplomat

\begin{abstract}
In the quest to create cutting-edge products, organizations often invest substantial time, attention, and capital in primary research and development (R\&D). By themselves, these $R \& D$ investments to create avant-garde products may not provide good return-on-investment. In the context of Canadian businesses, there is a significant scarcity of resources available for R\&D. What can Canadian firms do to stay innovative when they face a plethora of difficulties, including insufficient funding? This article explores how organizations can leverage external innovation and existing technologies to create products or services that cater to the market needs. We present a three-pillar model along with examples of companies that attained market success in large part by contextualizing existing technologies in order to create innovative products or services. This approach provides companies with a high-level framework to facilitate resource-parsimonious creation of commercializable, innovative products that are competitive in today's global marketplace.
\end{abstract}

\section{Introduction}

One of the truisms regarding innovation is that one should not try to "reinvent the wheel" or "discover how to do something that has already been discovered" (Cambridge Dictionary of American Idioms, 2003; tinyurl.com/n668msr). When business people fail to recognize the value of something "not invented here" or perhaps fail to recognize that an outside innovation exists at all, a great deal of effort can be wasted. However, we argue that broader attention to context is necessary for market success, and that leveraging existing technologies toward the creation of products or services that are attractive to the market can provide a less resource intensive path to successful innovation. Some degree of "reinvention" in order to contextualize an innovation promotes greater value creation across a variety of settings. This means that such reinvention is, in fact, not a rediscovery of something already discovered, but rather an extension of it. A novel combination of existing elements constitutes every bit as much innovation in terms of value creation and market opportunity as the creation of fundamentally new elements.
The notion of a social system within which innovations are situated and communicated implies the need to contextualize innovations for consumption in a given market. A focus on contextualizing innovations that appear elsewhere in order to make them more compatible with changing market demands or expectations - either adding new elements, subtracting others, or combining existing elements in new ways - provides businesses with the opportunity to reap substantial benefits without the need for far-reaching and time-consuming investment to create innovations from whole cloth. The other edge to the sword of focusing on such "reinvention" is that it may reduce the capacity of firms to engage in the kind of ground-breaking innovation that may generate leadership positions in global markets. However, as the experience of BlackBerry (tinyurl.com/ bjucast) makes clear, failure to reinvent one's own wheel from time to time in order to address specific market concerns is a path fraught with risks of its own.

However, one of the critical issues facing businesses in general, and Canadian businesses specifically, is the lack of resources for fundamental research and develop- 


\title{
Contextualizing Existing Innovations as a Path to Market Success
}

\author{
Jeff Moretz, Karthik Sankaranarayanan, and Jennifer Percival
}

ment spending (Council of Canadian Academies, 2013; tinyurl.com/mnyypck). In addition, firms that expend considerable resources on in-house research and development (R\&D) may face difficulty and delays in achieving returns on those investments. They may also fall prey to the "not invented here" syndrome (tinyurl.com/yuwk96). Such issues with a focus on foundational R\&D are significant and well known. Yet, when assessing the market prospects of firms, particularly firms in the high-technology sector, a great deal of attention is paid to fundamental innovation activities as represented by spending on R\&D (Booz \& Company, 2012: tinyurl.com/ 19sf76z; Hall and Lerner, 2010: tinyurl.com/mr4hvro), with Canadian investment significantly lagging behind the global field (Conference Board of Canada, 2013; tinyurl.com/mu6b946). The value ascribed to patenting implies that firms that invest extensively in R\&D will exhibit superior performance because of their activities in developing new technologies and products for which there is little viable competition and for which they can protect the underlying intellectual property (e.g., Arora et al., 2003; tinyurl.com/ljsqbfx). However, there is evidence that extensive $R \& D$ spending does not lead inexorably to superior performance (Boulding and Staelin, 1995; tinyurl.com/llnql53). In fact, high spending on R\&D may not even lead to superior innovativeness. Fast Company's annual list of the most innovative companies in 2012 (tinyurl.com/7hk5k4j) includes none of the top $R \& D$ spenders listed by Forbes (Hartung, 2012; tinyurl.com/b5qykex). Forbes points out that these high spending R\&D companies are not particularly good investments. Faced with such a wide array of difficulties with respect to innovation, what are firms to do? We argue that firms should rebalance their resources by focusing greater effort on tailoring innovations to particular market demands.

Technologically and commercially successful innovation requires a combination of three basic knowledge types: technical expertise, market knowledge, and organizational skill. These three building blocks form a solid foundation for bringing innovations to market successfully and profitably. Technical knowledge is necessary, but mere technical savvy is insufficient to the task of developing a commercially viable product or service. Firms must also possess sufficient understanding of the market to which a particular product or service is to appeal. Such market knowledge allows the packaging of technical capabilities into something that provides sufficient value to a buyer to induce a profitable transaction for the seller. Thus, this knowledge allows firms to address the needs of a target market, facilitating ac- ceptance of the innovative product and diffusion of the innovation (Rogers, 2010; tinyurl.com/ntrq2f6). Yet, the specific combination of elements will depend in part on the firm's underlying set of resources and capabilities (Barney, 1995; tinyurl.com/mcay3sk), which will differ from those of competitors. As Michael Porter (1996; tinyurl .com/pquath) argues, companies cannot be all things to all customers, but must make tradeoffs that provide a sustainable strategic position that is different from that of any competitor. Finally, firms must possess sufficient managerial or organizational proficiency to construct, control, and continue the systems that support product development, manufacturing, service delivery, commercialization, and subsequent product development efforts (Wang et al., 2010; tinyurl.com/lbmtnex). We propose that these elements represent the three pillars of commercializable innovation, as depicted in Figure 1.

In this article, we argue that paying greater attention to the requirements of a target market can reduce the need for costly and time-consuming foundational technological development while providing substantial opportunity for successful commercialization. We address each of these aspects of innovation, market-focused development, technical development capacity, and organizational capacity, with reference to realworld innovation examples. The examples include earlier innovation efforts that leveraged the approach discussed in the article as well as ventures that have chosen this approach more recently.

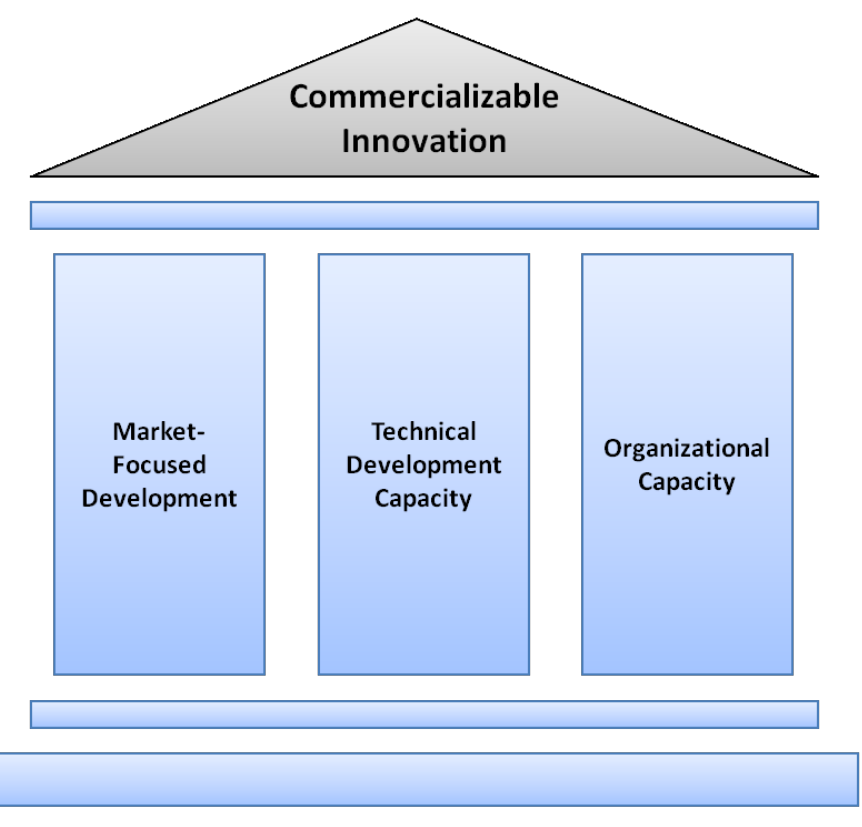

Figure 1. Pillars of innovation value 


\title{
Contextualizing Existing Innovations as a Path to Market Success
}

\author{
Jeff Moretz, Karthik Sankaranarayanan, and Jennifer Percival
}

\section{Market-Focused Development}

Although sufficient technical capacity to create a functional product or service system is a prerequisite for developing substantially new products or services, there is a significant market element in the success of any innovation in terms of firm performance. In order to profit from investment in innovation, a firm must create innovative products or services that provide sufficient and recognizable value for some set of buyers. There has been a great deal of disagreement regarding measures of product development (Griffin and Page, 1996; tinyurl.com/kq2ctxv); however, the metrics used in engineering - in which quality is assessed in terms of the degree to which the final output meets the specifications set for the development project - are not particularly useful measures for successful product development at the firm level. This engineering approach to measuring quality captures the capability of meeting design goals, yet it ignores the possibility that management may misapprehend the actual desires of the market, and thus may successfully produce a "high quality" product with limited potential for market success. Attention to marketing in addition to technical development efforts has the potential to dramatically increase the adoption and value-creation possibilities of new products (Dutta et al., 1999; tinyurl.com/n2ov39s).

Market success requires the combination of multiple elements into a package that creates greater perceived value for buyers than competing offerings (Yang and Kang, 2008; tinyurl.com/lsg9exx). Highly innovative companies, such as number 1 on the Fast Company list (2012; tinyurl.com/7hk5k4j), Apple, create highly valued offerings that combine numerous technologies. Many of the technologies in the iPhone and iPad were developed from the ground up in Apple facilities. However, Apple has also leveraged outside innovation since the 1970s. As Malcolm Gladwell points out in his article "Creation Myth" (2011; tinyurl.com/3fmz4ee), many of the technologies employed in the creation of Apple's first gangbuster market success, the Macintosh, were first developed by Xerox Corporation at the legendary Palo Alto Research Center (PARC; parc.com). PARC researchers had developed the graphical user interface (GUI), the computer mouse, the WYSIWYG text editor, and the first iterations of Ethernet. However, despite this panoply of technologies that, in retrospect, are obvious to us all as sources of tremendous value, Xerox failed to achieve significant market success with any of them. The success of Apple was a combination of product development and market savvy. Jobs and com- pany took the kernel of the ideas produced at Xerox PARC and developed a functional system that provided exceptional customer value by fundamentally altering the way people interacted with computers. However, this transformation was not instantaneous, cheap, or even obvious (except in hindsight). Apple first developed the Apple Lisa, a radically overpriced and under-capable machine that was a colossal market failure. Only through extensive subsequent development was the company able to create the market success that was Macintosh.

\section{Technical Development Capacity}

Of course, all of the marketing capability in the world will generate little profit without sufficiently functional technical elements. McDonald's possesses one of the world's most valuable brands (Interbrand, 2012; tinyurl.com/9v2haam), but it is the service delivery technology - primarily McDonald's highly developed food service processes - that create the consistency and reliability upon which the brand rests. In the high-technology domain, technical development capacity is critical for producing a product that has the capabilities that a firm can market to customers. Such technological know-how is generally expensive to maintain, but it is a cost of doing business in the high-technology sphere. However, firms need not maintain exceptionally high expenditures on ground-breaking fundamental research in order to possess sufficient technical development capacity to produce eminently saleable products.

The example of the feedback between Apple and Xerox PARC helps to make this point clear. In the development of the computer mouse, Xerox PARC researchers began the development of the idea created by a Stanford researcher, and the engineers at Apple evolved it still further into a simple product that integrated well with a simplified computer operating environment with dramatically more intuitive controls that facilitated work that people wanted to accomplish (Gladwell, 2011; tinyurl.com/3fmz4ee).

The fact that Xerox PARC was located where it was, rather than close to the east coast headquarters of Xerox Corporation, was no accident. The PARC was one player among many in the Silicon Valley cluster of hightechnology development. By positioning research centres in the same geographical area, firms were able to leverage significant concentrations of knowledge and supporting services that would have been difficult to ac- 


\title{
Contextualizing Existing Innovations as a Path to Market Success
}

\author{
Jeff Moretz, Karthik Sankaranarayanan, and Jennifer Percival
}

cess elsewhere. The firms in Silicon Valley also leveraged proximity to world-class research universities. Stanford University and the University of California, Berkeley provided access to cutting-edge research insights without the need for funding wide-ranging and expensive basic research.

Another significant entrepreneurial innovation success traces its roots to similar colocation. Research In Motion, now BlackBerry (tinyurl.com/y5c86x), is headquartered in the Kitchener-Waterloo area that is home to myriad technology companies. This colocation provides a critical mass of science and engineering talent, support services and capabilities, and technologically savvy collaborators, colleagues, and competitors with whom science and engineering staff can exchange thoughts and ideas. The proximity to the University of Waterloo and its engineering and technology capabilities is no accident. Research in Motion hired hundreds of Waterloo graduates over the years to assist with product development efforts.

Similar to the example of Apple, Research In Motion (now BlackBerry) did not invent most of the foundational technologies that it utilized. The Mobitex network standard (tinyurl.com/5b69t7) for packet-switched wireless data transmission was developed in Scandinavia by a joint venture between Ericsson and Televerket, the Swedish telecommunications agency. Research in Motion engineers eventually developed a method for sending and receiving messages, leading to the creation of two-way wireless communication devices and, a few years later, the first BlackBerry device. By leveraging existing technology that facilitated secure and reliable communications, Research In Motion was able to create a dominant market presence in business communications where such security and reliability were highly prized. However, it was not the underlying technology that created Research In Motion's success, but rather the combination of technological knowledge and market knowledge, along with the organizational capacity to bring the resulting product to market.

A more recent startup in Toronto is using a similar approach to developing a service offering. Syngrafii (syngrafii.com) leverages the LongPen technology developed for Margaret Atwood (tinyurl.com/ywwzlc). Atwood invented the LongPen in order to enable remote booksigning events. The complete solution that Atwood conceived allows audio and video transmission in addition to a pen and ink remote signature that is an exact duplicate of the signature produced by the signer. The concep- tion of this technology is quintessentially Canadian, inspired by the vast landscape across which Canadians seek to communicate and collaborate.

The commercialization approach taken by Syngrafii is to convert this foundational technology into solutions for remote signing of legal documents. The service has the advantages of remote signatures while avoiding the necessity of radically altering existing business processes that are based upon physical signatures. Although the advantages to such an approach may seem obvious, Syngrafii has undertaken additional development in order to make the technology viable for legal documents. The foundational technology is fully functional for remote book signings in which participants are generally satisfied with the synchronous video-conferencing as a guarantee of the legitimacy of the signature; however, it requires additional development to meet the requirements for verifiable legal signatures. Yet, by starting with a technology that has proven capability to meet a critical subset of the task requirements, Syngrafii is far ahead of the game in developing a remote-signature solution that produces physical signatures (as opposed to purely digital signatures, which are far less appealing to potential customers such as banks because they diverge so radically from the signatures for which legal precedents exist).

Syngrafii is thus utilizing a prior technological development in order to move into a new market space by redefining what that technological development can do. Such reconceptualization of existing technology requires additional technical work, and it certainly requires additional adaptation to fit a specific target market's needs, but it is a much less fraught and lesstime consuming approach to developing innovative offerings.

\section{Organizational Capacity}

The combination of functional technological elements with viable market positioning and compelling customer value is accomplished through the marshalling of a vast array of resources, capabilities, and connections. The creation of innovative technology alone is insufficient. A firm must also possess a culture that values innovation, is capable of assimilating innovations, and can turn new developments into viable market offerings (Wang et al., 2010; tinyurl.com/lbmtnex). An attractive market position without capable product or service technology is a recipe for long-term disaster, though the persistence of vaporware, products that are an- 


\title{
Contextualizing Existing Innovations as a Path to Market Success
}

\author{
Jeff Moretz, Karthik Sankaranarayanan, and Jennifer Percival
}

nounced but never produced, argues that there may be some short-term advantage to staking out mindshare in the market even absent a viable technological solution. It is the combination of an array of complementary resources and capabilities that creates real and lasting value in the marketplace and the exchange. Firms that lack this capability of organizing and managing the interconnections between the elements of a market offering suffer reduction in profitability or market share or reputation/brand image. Organizational capacity is the glue that binds all of the firm's capabilities into a coherent system that can deliver customer value.

Over the long haul, persistent lack of organizational capacity results in a loss of brand reputation, market share, and profitability. Apple suffered just such an attrition of market position in the 1990s as the appeal of its products diminished, the brand name slid in public perception, and corporate results were so poor that many market watchers expected bankruptcy. Some even went so far as to call Apple "arguably one of the worst-managed companies in the industry" (Intelligent Speculator, 2011; tinyurl.com/pol23qr). Similar speculation has been made regarding the prospects of BlackBerry (the new name taken by Research In Motion after its recent near-death experiences). Both companies suffered a failure of management that led to ineffective use of the technical and marketing capacities they had developed. Apple navigated its organizational crisis to emerge as a market leader in the commercialization of technology, though it still ranks well down the list of big spenders on $R \& D$ relative to size. One of the chief components of Apple's success has been the creation of effective mechanisms for capitalizing on the creations of others in order to provide customer value. The success of Apple's flagship products relies as much on iTunes and the App Store as it does on Apple's product innovations. BlackBerry might manage a similar renovation to reestablish itself as an innovation leader, but doing so would require radical improvement of the overarching organizational capacity necessary for pulling myriad disparate pieces of technological and market knowledge together into an attractive and saleable package.

\section{Conclusion}

The constraints faced by many businesses in terms of resources available for fundamental research and development are well known. However, these constraints need not be prohibitive of innovation success. The model proposed in this paper addresses the difficulties faced by innovating businesses, particularly innovators operating in environments with modest $R \& D$ resources, by highlighting the value of identifying and exploiting market opportunities that leverage existing technologies and packaging them into commercializable product or service innovations. Firms that seek commercialization opportunities utilizing existing technologies can achieve substantial success in the marketplace.

In order to capitalize on technological innovation, firms must have sufficient capabilities in three core areas: technical development, market knowledge, and organizational capacity. Technical development capabilities are necessary in order to turn any single technology into a saleable product or service. Reconfiguration allows firms to start farther along the technical development curve, but it does not eliminate the need for technical capabilities. By reconfiguring existing technologies, firms reduce the need for R\&D spending on foundational technology. Although this approach might seem to limit the degree of intellectual property protection a firm could leverage, the examples above show that such concerns need not be prohibitive. Market knowledge is critical for turning any technology into an offering that is attractive to a focal market. Firms that neglect market knowledge are likely to find their ability to profit from their technologies to be significantly constrained. Finally, firms must also develop sufficient organizational capacity to combine the technical capabilities and market knowledge into a saleable offering that instills confidence in buyers regarding quality and reliability. Thus, technical development capabilities are necessary, but extensive emphasis on fundamental research is not necessarily the most reliable path to market success. Although the specific approaches to divining the needs of various markets are manifold, many firms will find it advantageous to pay greater attention to knowledge of particular markets and their various needs and expectations. This approach can provide significant opportunities to leverage existing technologies to create value for customers and profits for those firms that reinvent the wheel, by packaging innovative components effectively.

\section{Recommended Reading}

- Booz \& Company: Global Innovation 1000 (2012; tinyurl.com/96rqmmt)

- McKinsey Global Institute: "Disruptive Technologies" (2013; tinyurl.com/nmbecug) 


\title{
Contextualizing Existing Innovations as a Path to Market Success
}

\author{
Jeff Moretz, Karthik Sankaranarayanan, and Jennifer Percival
}

\begin{abstract}
About the Authors
Jeff Moretz is Assistant Professor of Strategy and Entrepreneurship at the University of Ontario Institute of Technology (UOIT) in Oshawa, Canada. He obtained his PhD from the University of Texas at Austin, USA, and has an MBA and two undergraduate degrees from Michigan State University, USA. He is a recovering consultant, having worked for McKinsey \& Company in Chicago after his MBA studies. Prior to joining the UOIT, he worked at University College Cork in Ireland, researching open source software communities and open innovation. His research interests focus on the impact of information, openness, and information technologies on innovation, business models, and strategies.
\end{abstract}

Karthik Sankaranarayanan is an Assistant Professor of Operations Management at the University of Ontario Institute of Technology in Oshawa, Canada. He earned a PhD degree in Economics and a Master's degree in Embedded Systems from the University of Lugano, Switzerland, as well as a Bachelor's degree in Electrical and Electronics Engineering from the University of Madras in Chennai, India. Prior to joining UOIT, he was a visiting scholar at the New England Complex Systems Institute in Cambridge, USA, where he explored agent-based modelling of complex systems. His research encompasses simulation and modelling of complex systems, and the broader behavioural operations field. Recently, he has become involved in a collaborative study on the application of an open innovation framework in the services sector.

Jennifer Percival is Associate Professor and Associate Dean of Programs in the Faculty of Business and Information Technology at the University of Ontario Institute of Technology in Oshawa, Canada. She holds a BMath in Operations Research and a PhD in Management Sciences from the University of Waterloo, Canada. Her research focus is on the strategic use of technology and innovation, including the effective use of technological innovations in order to determine the optimal allocation of IT investments for various organizational cultures to support e-services and e-health initiatives. She is also actively involved in research surrounding the use of process-modelling techniques to support change management, innovation, and technology integration in services.
Citation: Moretz, J., K. Sankaranarayanan, and J. Percival. 2013. Reinventing the Wheel: Contextualizing Existing Innovations as a Path to Market Success. Technology Innovation Management Review. October 2013: 16-21.

Keywords: innovation management, commercialization, organization, market-focused innovation, contextualization of innovation 